\title{
Factors That Affect Reliability of Nondestructive Detection of Flaws in Structural Ceramics
}

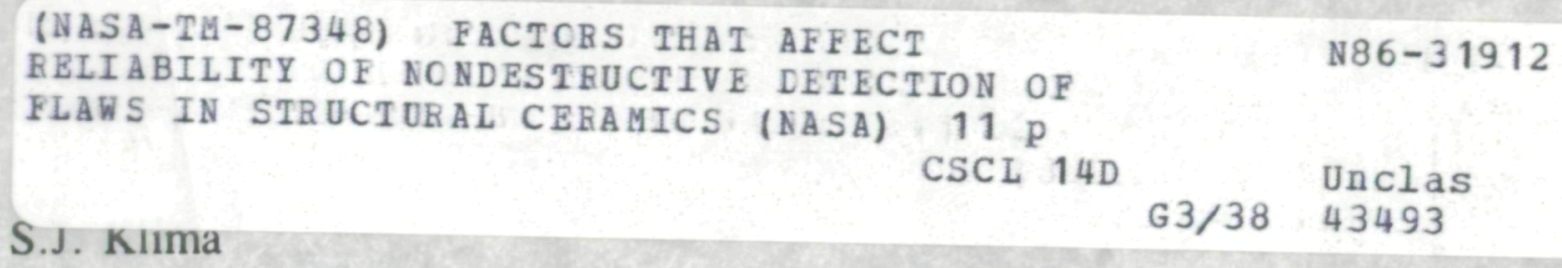

Lewis Research Center

Cleveland, Ohio

G.Y. Baaklini

Cleveland State University

Cleveland, Ohio

and

D.J. Roth

Lewis Research Center

Cleveland, Ohio

Prepared for the

2nd International Symposium on Ceramic Materials and Components for Engines cosponsored by the German Ceramic Society and the American Ceramic Society Lübeck-Travemünde, West Germany, April 14-17, 1986 
FACTORS THAT AFFECT RELIABILITY OF NONDESTRUCTIVE DETECTION OF FLAWS IN STRUCTURAL CERAMICS

\author{
S.J. Klima, * G.Y. Baaklini,** and D.J. Roth*
}

\title{
INTRODUCTION
}

The need for quantitative assessment of the reliability of flaw detection techniques arises from the application of fracture mechanics principles to the design of critical parts. The fracture mechanics concept assumes that flaws are present in all materials and quantitatively describes their effect on structural integrity. Thus, a critical crack size that would result in unstable crack growth can be defined for any combination of material and loading condition (Ref. 1). For simple components such as pressure vessels, fracture control. can be achieved by proof testing to a pressure which exceeds the operating stress. If the vessel does not fracture, the absence of critical flaws is assured. For complex structures however, proof testing logic may not be applicable because in many cases it is not possible to duplicate precisely the nature of operating stresses. Therefore, structural integrity of complex components must be established by a different approach, the most practical of which may be nondestructive evaluation (NDE). The role of NDE would be to screen out parts that contain flaws equal to or greater than the critical crack size before they are put into service (Ref. 2). It may further be necessary to guarantee that flaws smaller than the critical size are absent to account for possible sub-critical crack growth, especially when stress corrosion or fatigue cracking can occur.

The use of Eracture mechanics concepts in ceramic component design places a premium on the ability of nondestructive inspection to detect small defects (Refs. 3 and 4$)$, and on the need to determine the practical reliability of an NDE procedure when that procedure is considered for detection of flaws of a specific type and size (Ref. 5). Such information is essential if the designer is to rely on NDE to assure that components are free of flaws that exceed the critical size in the material chosen for a particular service environment. If the design is such that the critical crack size is greater than the smallest flaw that can be reliably detected (or the largest flaw that will be missed a significant proportion of the time) then the inspection process can be used. The difference between the smallest detectable flaw and the critical crack size can be regarded as a measure of the margin of safety.

\footnotetext{
*National Aeronautics and Space Administration, Lewis Research Center, Cleveland, Ohio 44135 U.S.A. $\star \star C l e v e l a n d$ State University, Cleveland, Ohio 44115 .
} 
The reliability of various conventional nondestructive techniques for detection of cracks in metallic aircraft engine components was reported in Ref. 6 . The only previously reported work on NDE detection reliability for flaws in heat engine ceramics is presented in Refs. 7 to 10. The purpose of this paper is to re-examine some of the factors that influence the detectability of minute flaws in ceramics, and focus attention on requirements for assuring adequate detection sensitivity and reliability.

SPECIMEN PREPARATION

Figure 1 shows a flow chart which describes the preparation of specimens containing seeded voids. The SiC starting powder contained sintering aids and binder material (boron and carbonaceous resins). The $\mathrm{Si}_{3} \mathrm{~N}_{4}$ starting powder contained 6 percent $\mathrm{Y}_{2} \mathrm{O}_{3}$ and 6 percent $\mathrm{SiO}_{2}$ to promote densification while sintering. For surface voids, all of the powder necessary to make up the specimen thickness was poured into the die and the microspheres were pressed into the top surface. For internal voids the amount of powder put in the die before and after placement of the microspheres was controlled to achieve the desired void depth in the finished specimen. The die pressed bars were vacuum sealed in latex tubing and cold isopressed to approximately 60 percent of full density. After removing the latex the compacts were heated in vacuum to vaporize the plastic microspheres. The as-sintered density of silicon carbide ranged from 94 to 97 percent of theoretical while for silicon nitride it was more than 98 percent of full theoretical density. As-fired test bars measured nominally $28 \mathrm{~mm}$ long, $7 \mathrm{~mm}$ wide, and 2 to $4 \mathrm{~mm}$ thick, as required for NDE reliability determinations. After NDE, internal voids were exposed by diamond grinding and measured by optical and electron microscopy. These data are listed in Table I. The dimensions of voids in green compacts were assumed to be equivalent to the seeded spheres. Details on specimen fabrication and void characterization are given in Ref. 10 .

\section{NDE AND STATISTICAL ANALYSIS}

The reliability of microfocus radiography and scanning laser acoustic microscopy (SLAM) for detection of seeded voids was evaluated. Schematic diagrams of the two NDE techniques are shown in Figs. 2 and 3 . The $x-r a y$ system, with a molybdenum anode, was operated in the 30 to $60 \mathrm{kV}$ range which produced photon energies between 17 and $20 \mathrm{keV}$. Higher photon energy levels were found to result in reduced film contrast which is undesirable. Radiographic images at a magnification of 2.5 were made by the projection method and examined with the aid of an X7 optical magnifier.

With the SLAM technique (Fig. 3), $100 \mathrm{MHz}$ ultrasonic waves transmitted through the specimen are modulated by material surface and internal characteristics. The relative intensity and phase of the waves reaching the reflective film on the cover slip are detected by a laser beam raster scanned over an area approximately 2.4 by $2 \mathrm{~mm}$. 
The beam is reflected into a photodetector and converted to an electronic signal. Thus, an image of the acoustic perturbations caused by features such as cracks, voids, density variations, etc., are displayed in real time on a video monitor at a magnification of nearly X100. Reference 7 describes the SLAM technique in greater detail. Due to uncertainties associated with equipment, operator, flaw characteristics, etc., the detection of flaws in engineering materials and. components is probabilistic in nature and must be evaluated using a statistical approach. Since an attempt at detection of a given flaw can have only two possible outcomes (it is either detected or missed) the probability of detection (POD) can be described by the binomial distribution. The flaws were grouped into size intervals because large numbers of voids of discrete size were not attainable due to fabrication variables. The probability of detection was calculated for each interval by the "optimized probability" method described in Ref. 5. A fortran computer program that calculates and plots NDE reliability data is listed in Ref. 7 (NASA TM only).

\section{RESULTS AND DISCUSSION}

NDE reliability data for the microfocus $x-r a y$ technique is presented in Figs. 4 and 5 in the form of plots of probability of detection versus void size, expressed as a percent of total specimen thickness. As shown in Table I, the internal void diameters ranged from 50 to $528 \mu \mathrm{m}$ in the green specimens and 20 to $477 \mu \mathrm{m} \cdot$ in the fully densified bars.

All of the POD curves are characterized by a sharp drop in probability of detection in a region below approximately 2.5 percent thickness sensitivity. Figure $4(a)$ shows that the detection sensitivity of internal voids in green silicon nitride is nearly the same as in green silicon carbide, approximately 2.5 percent at a POD of 90 percent. The curves in Figs. 4(b) and (c) are more revealing, showing that surface voids are more easily detected than internal voids for both materials. Analysis of a limited number of internal voids in green compacts showed that they were partially filled with loose powder, which has the effect of reducing the contrast on the $x$-ray film. This could account for the lower apparent sensitivity. In naturally occurring voids this may be less of a problem because they are not usually produced by vaporizing a supporting material such as the seeded spheres. The POD data for surface voids presented here would probably apply to naturally occurring internal voids in green materials produced by dry pressing as well as by other techniques such as injection molding and slip casting. For sintered materials, the data in Fig. 5 show many interesting features. For example, Fig. 5(a) indicates unusually good sensitivity to internal voids in silicon nitride. However, chemical analysis of void walls (Ref. 10) proved that detection of some internal voids in silicon nitride was influenced by a deposit of yttrium, a strong absorber of x-rays. Thus, some of the voids 
appeared to have a high density shell on the radiograph, resulting in enhanced detectability. This condition could occur in any sintered material that utilizes sintering aids composed of heavy elements. A similar phenomenon was not observed with voids seeded in silicon carbide (Figs. 5 (b) and (c)). NDE reliability for SLAM is presented in Figs. 6 and 7. Figure 6, which contains data for surface connected voids only (Ref. 7) shows the effect of surface condition and specimen thickness on detectability of flaws. From the POD curves for as-fired specimens, it is evident that 0.90 probability of detection at 0.95 confidence level was not attained for any thickness down to $2 \mathrm{~mm}$. When the same specimens were lightly polished to a surface finish of nominally $2 \mu \mathrm{m}$, the POD was significantly improved. POD of 0.90 was achieved at all thicknesses. Thus, it appears that as-fired surfaces cause a background noise level higher than can be tolerated for nondestructive detection of minute defects by SLAM. The measured surface finish of as-fired samples was $8 \mu \mathrm{m}$ (peak-to-valley) but it should be noted that topography was the only surface characteristic that was measured. It is possible that other factors such as fine nearsurface porosity, acting as ultrasonic wave scatterers, could have contributed to the generally low POD for as-fired samples.

Figure 7 shows a plot which summarizes POD data obtained for internal voids in specimens with diamondground surfaces (Ref. 9). The boundaries of the bar graphs indicate the maximum void sizes and depths (from the laser-scanned surface) at which $0.90 / 0.95$

$\mathrm{POD} / \mathrm{confidence-level}$ was achieved. As expected, there is a significant effect of void size and depth. However, the plot also shows that $0.90 / 0.95$ is obtained at greater depths and smaller void sizes in silicon nitride than in silicon carbide. This is probably due to differences in microstructure between the two materials. The grain size in silicon carbide was an order of magnitude greater than in silicon nitride. The bulk porosity in silicon carbide was also higher than in silicon nitride. Both of these conditions would have the effect of increasing ultrasonic scatter, thereby reducing the POD of voids in silicon carbide relative to silicon nitride.

\section{CONCLUSION}

Reliability of void detection in ceramics by microfocus radiography was affected by various material and process related parameters. It was observed that photon energy levels less than $20 \mathrm{keV}$ produced better radiographic contrast and hence better void detectability than higher energy levels. Migration of yttrium to the region surrounding void walls enhanced the detectability of voids in many, but not all sintered silicon nitride specimens. The sensitivity of $x$-rays to voids in green silicon carbide and silicon nitride compacts was reduced by the presence of loose powder inside the cavity. 
Reliability of void detection by scanning laser acoustic microscopy was affected by a different set of parameters. The larger grain size and higher relative porosity in sintered silicon carbide resulted in significantly reduced detection capability than was observed for silicon nitride. Void detection in both materials was greatly improved when the as-sintered surface was removed by surface grinding or polishing.

\section{REFERENCES}

1. Kanninen, M.F.; and Popelar, C.H.: Advanced Fracture Mechanics, Oxford University Press, New York, 1985.

2. Packman, P.F.: Fracture Toughness and NDT Requirements for Aircraft Design. Nondestr. Test., Vol. 6, no. 6, Dec. 1973, pp. 314-324.

3. Bradt, R.C.; Hasselman, D.P.H.; and Lange, F.F.; eds.: Fracture Mechanics of Ceramics. Vols. 1-2, 1974; Vols. 3-4, 1978. Plenum Press, New York.

4. Rice, R.W., et al.: Failure Causing Defects in Ceramics; What NDE Should Find. NRL-MR-4075, Naval Research Laboratory, Oct. 1979. (AD-A078234)

5. Packman, P.F., et al.: Reliability of Flaw Detection by Nondestructive Inspection. Metals Handbook, Vol. 11 - Nondestructive Inspection and Quality Control, 8th ed., American Society for Metals, Metals Park, OH, 1976, pp. 414-424.

6. Rummel, W.D., et al.: Reliability of Nondestructive Inspection (NDI) of Aircraft Engine Components. SAALC/MM-8151, San Antonio Air Logistics Command, Jan. 1984. (AD-A155320)

7. Roth; D.J., et al.: Reliability of Void Detection in Structural Ceramics by use of Scanning Laser Acoustic Microscopy. Mater. Eval., Vo1. 44, no. 6, May 1986, pp. 762-769, 761. Also, NASA TM-87035, Mar., 1985.

8. Baaklini, G.Y.; Kiser, J.D.; and Roth, D.J.: Radiographic Detectability Limits for Seeded Voids in Sintered Silicon Carbide and Silicon Nitride. Advanced Ceramic Materials, Vol. 1, no. 1, Jan. 1986, pp. 43-49.

9. Roth, D.J.; and Baaklini, G.Y.: Reliability of Scanning Laser Acoustic Microscopy for Detecting Internal Voids in Structural Ceramics. Advanced Ceramic Materials, Vol. 1, no. 3, July 1986.

10. Baaklini, G.Y.; and Roth, D.J.: Probability of Detection of Internal Voids in Structural Ceramics Using Microfocus Radiography. NASA TM-87164, 1985. 
TABLE I. - DIMENSIONS OF SEEDED INTERNAL VOIDS. GEOMETRY SIMILAR TO AN OBLATE SPHEROID, WITH AXIS IN THE DIRECTION OF SPECIMEN THICKNESS

\begin{tabular}{|c|c|c|c|c|c|c|}
\hline \multirow[t]{3}{*}{ Material } & \multirow{3}{*}{$\begin{array}{c}\text { Original } \\
\text { sphere } \\
\text { diameter, } \\
\mu \mathrm{m}\end{array}$} & \multirow{3}{*}{$\begin{array}{l}\text { Number of } \\
\text { spheres } \\
\text { seeded }\end{array}$} & \multicolumn{4}{|c|}{ Dimensions after sintering } \\
\hline & & & \multicolumn{2}{|c|}{ Axis, $\mu \mathrm{m}$} & \multicolumn{2}{|c|}{ Diameter, $\mu \mathrm{m}$} \\
\hline & & & Mean & $\begin{array}{l}\text { Standard } \\
\text { deviation }\end{array}$ & Mean & $\begin{array}{l}\text { Standard } \\
\text { deviation }\end{array}$ \\
\hline $\mathrm{Si}_{3} \mathrm{~N}_{4}$ & $\begin{array}{r}80 \\
115 \\
200 \\
321 \\
528\end{array}$ & $\begin{array}{l}69 \\
39 \\
31 \\
28 \\
21\end{array}$ & $\begin{array}{r}20 \\
37 \\
133 \\
233 \\
307\end{array}$ & $\begin{array}{r}4 \\
5 \\
17 \\
16 \\
14\end{array}$ & $\begin{array}{r}25 \\
68 \\
139 \\
267 \\
386\end{array}$ & $\begin{array}{r}6 \\
5 \\
8 \\
18 \\
15\end{array}$ \\
\hline $\mathrm{SiC}$ & $\begin{array}{r}50 \\
80 \\
115 \\
200 \\
321 \\
528\end{array}$ & $\begin{array}{l}50 \\
47 \\
68 \\
19 \\
39 \\
43\end{array}$ & $\begin{array}{r}32 \\
59 \\
77 \\
165 \\
297 \\
477\end{array}$ & $\begin{array}{r}3 \\
6 \\
10 \\
29 \\
19 \\
47\end{array}$ & $\begin{array}{r}58 \\
100 \\
131 \\
194 \\
307 \\
505\end{array}$ & $\begin{array}{r}3 \\
8 \\
8 \\
11 \\
15 \\
28\end{array}$ \\
\hline
\end{tabular}




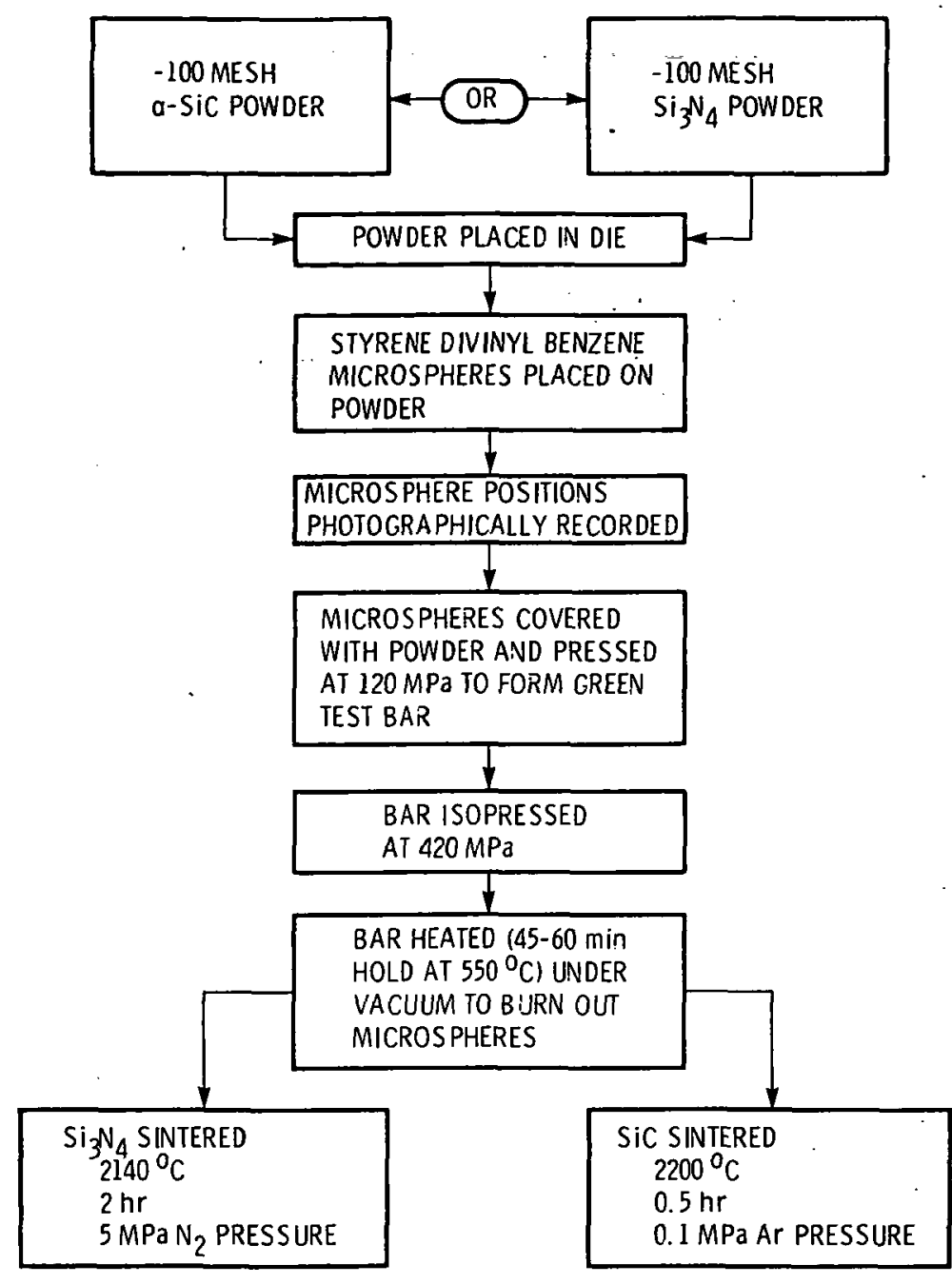

Figure 1. - Fabrication of silicon nitride and silicon carbide test specimens with seeded internal voids.

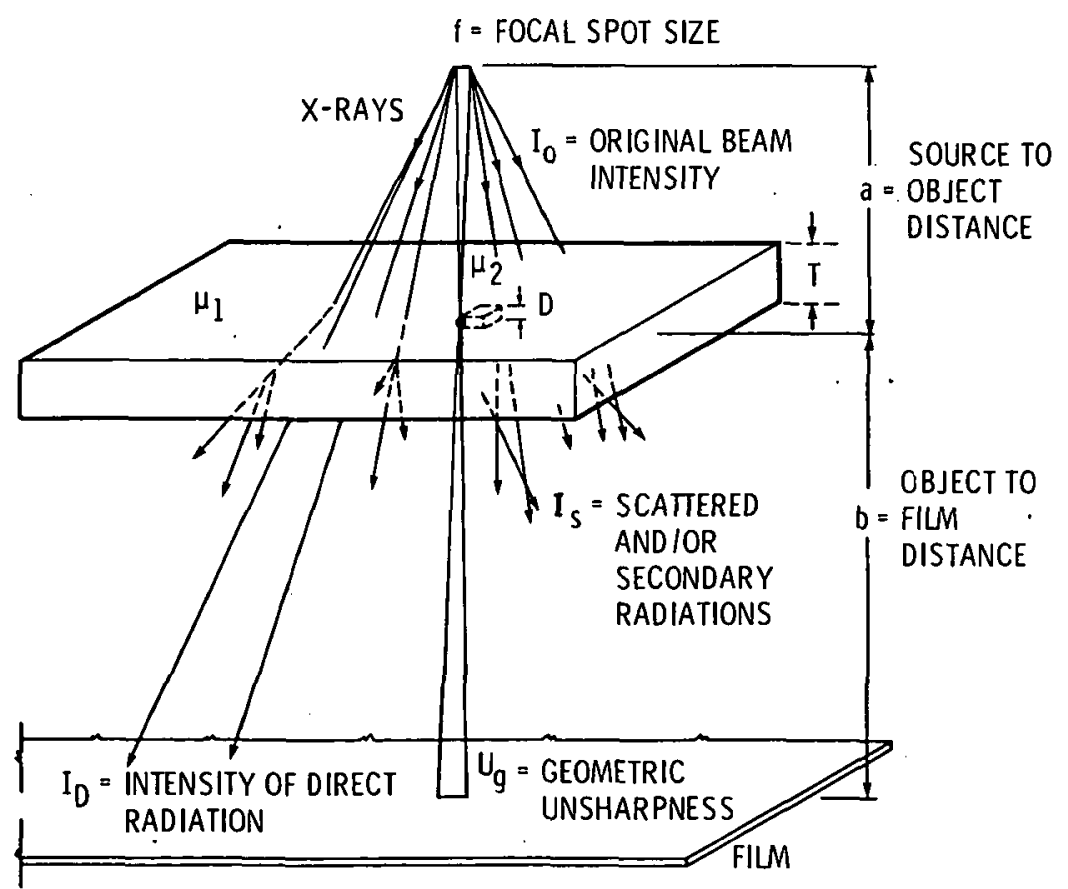

Figure 2. - A schematic configuration of microfocus projection radiography, where $D$ is thickness of defect, $T$ is thickness of sample, $\mu_{1}$ is attenuation 'coefficient of the matrix, and $\mu_{2}$ is attenuation coefficient of the defect. 


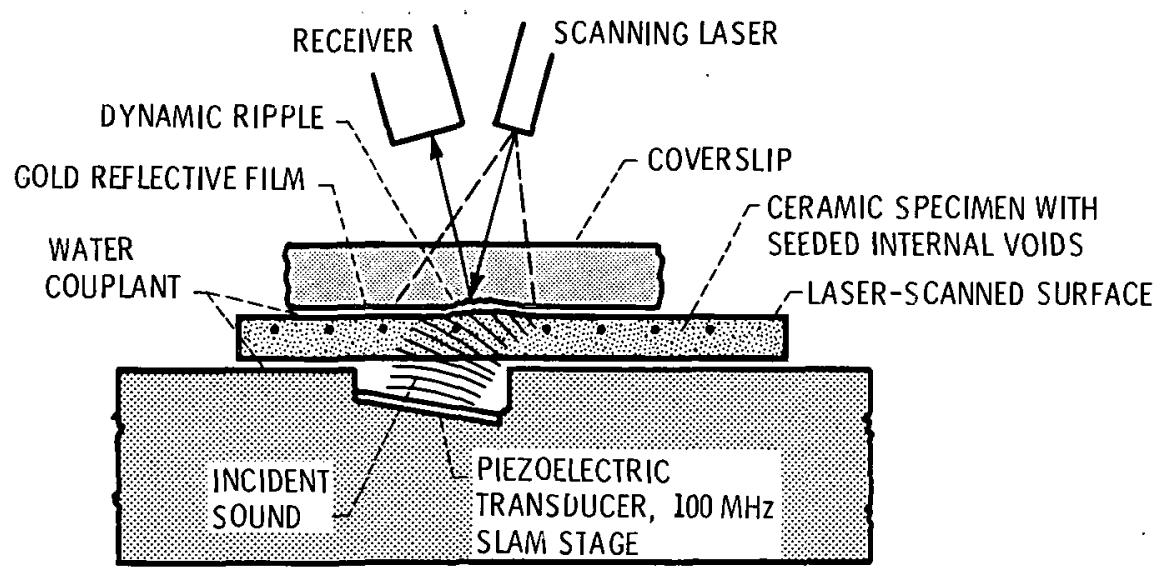

Figure 3. - Scanning laser acoustic microscopy (SLAM) of ceramic test bars containing seeded internal defects.

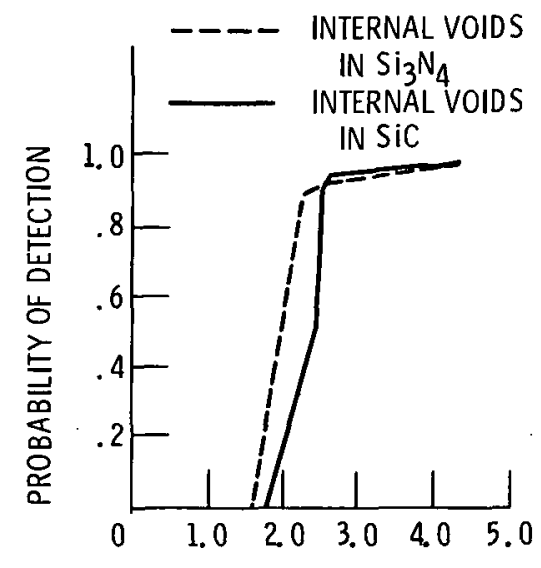

(a) Green $\mathrm{SiC}$ and $\mathrm{Si}_{3} \mathrm{~N}_{4}$.

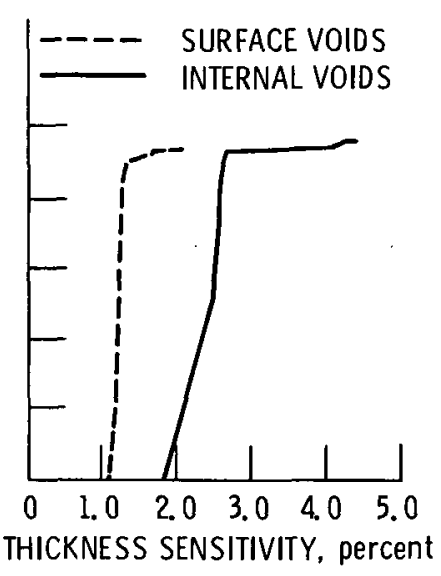

(b) Green SiC.

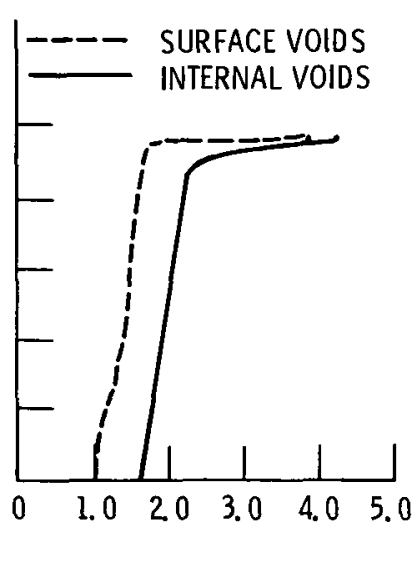

(c) Green $\mathrm{Si}_{3} \mathrm{~N}_{4}$.

Figure 4. - Lower bound probability of detection by microfocus $x$-ray of surface and internal voids in green isopressed $\mathrm{SiC}$ and $\mathrm{Si}_{3} \mathrm{~N}_{4}$ bars calculated at 95 percent confidence level. Thickness sensitivity, $\%=100$ (void dimension in $x$-ray beam direction)/(thickness of specimen in same direction).

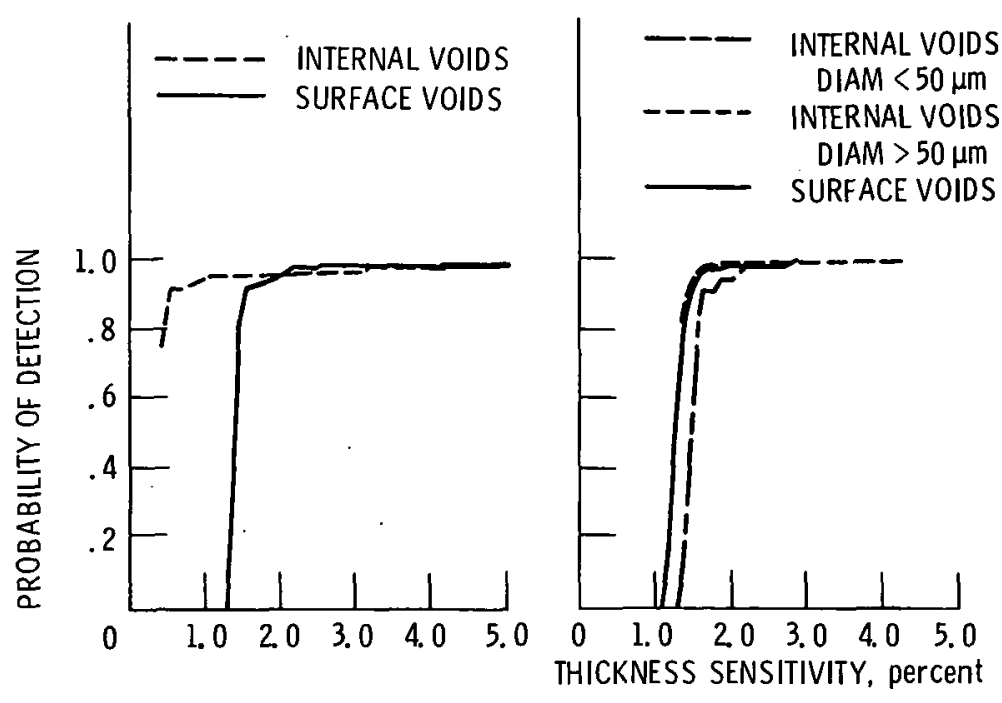

(a) Sintered $\mathrm{Si}_{3} \mathrm{~N}_{4}$.

(b) Sintered SiC.

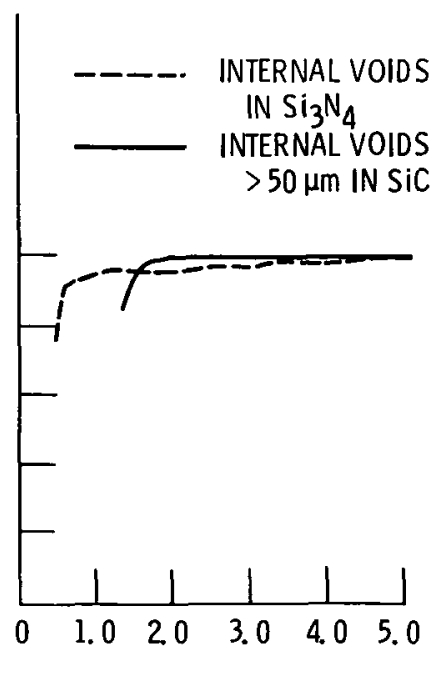

(c) Sintered $\mathrm{SiC}$ and $\mathrm{Si}_{3} \mathrm{~N}_{4}$.

Figure 5. - Lower bound probability of detection by microfocus x-ray of surface and internal voids in sintered $\mathrm{SiC}$ and $\mathrm{Si}_{3} \mathrm{~N}_{4}$ bars calculated at 95 percent confidence level. Thickness sensitivity, $\%=100$ (void dimension in $x$-ray beam direction)/(thickness of specimen in same direction). 

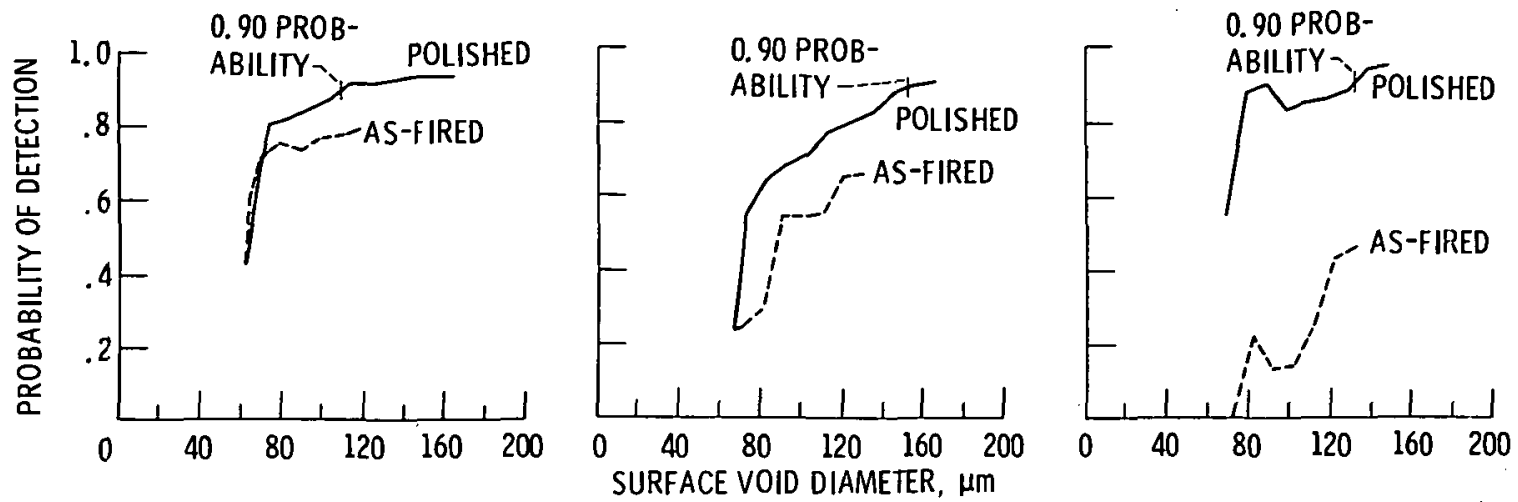

(a) $2 \mathrm{~mm}$ thick.

(b) $3 \mathrm{~mm}$ thick.

(c) $4 \mathrm{~mm}$ thick.

Figure 6. - Effect of specimen thickness and surface condition on probability of detection of voids by SLAM in sintered silicon nitride. Effect of thickness is evident only for specimens with as-fired surfaces. Probability of detection calculated at 0.95 confidence level.

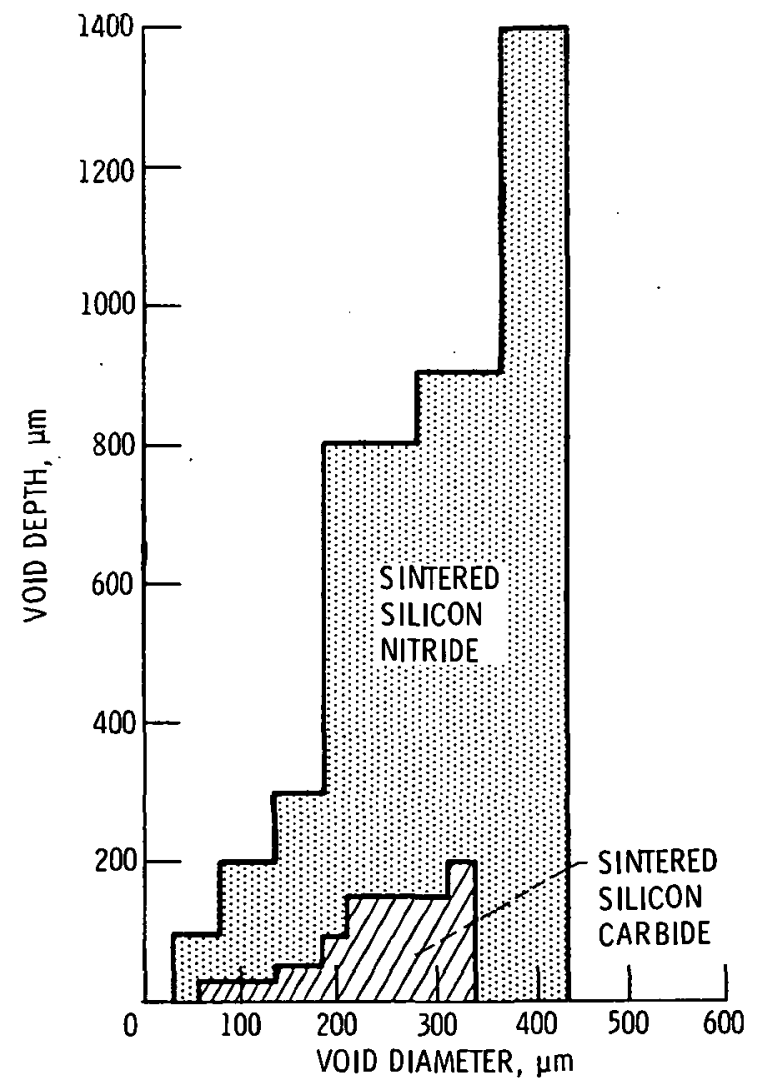

Figure 7. - Effect of void size, void depth, and matrix material on probability of detection of internal voids by scanning laser acoustic : microscopy. 0.90 Probability of detection at 0.95 confidence limit. 


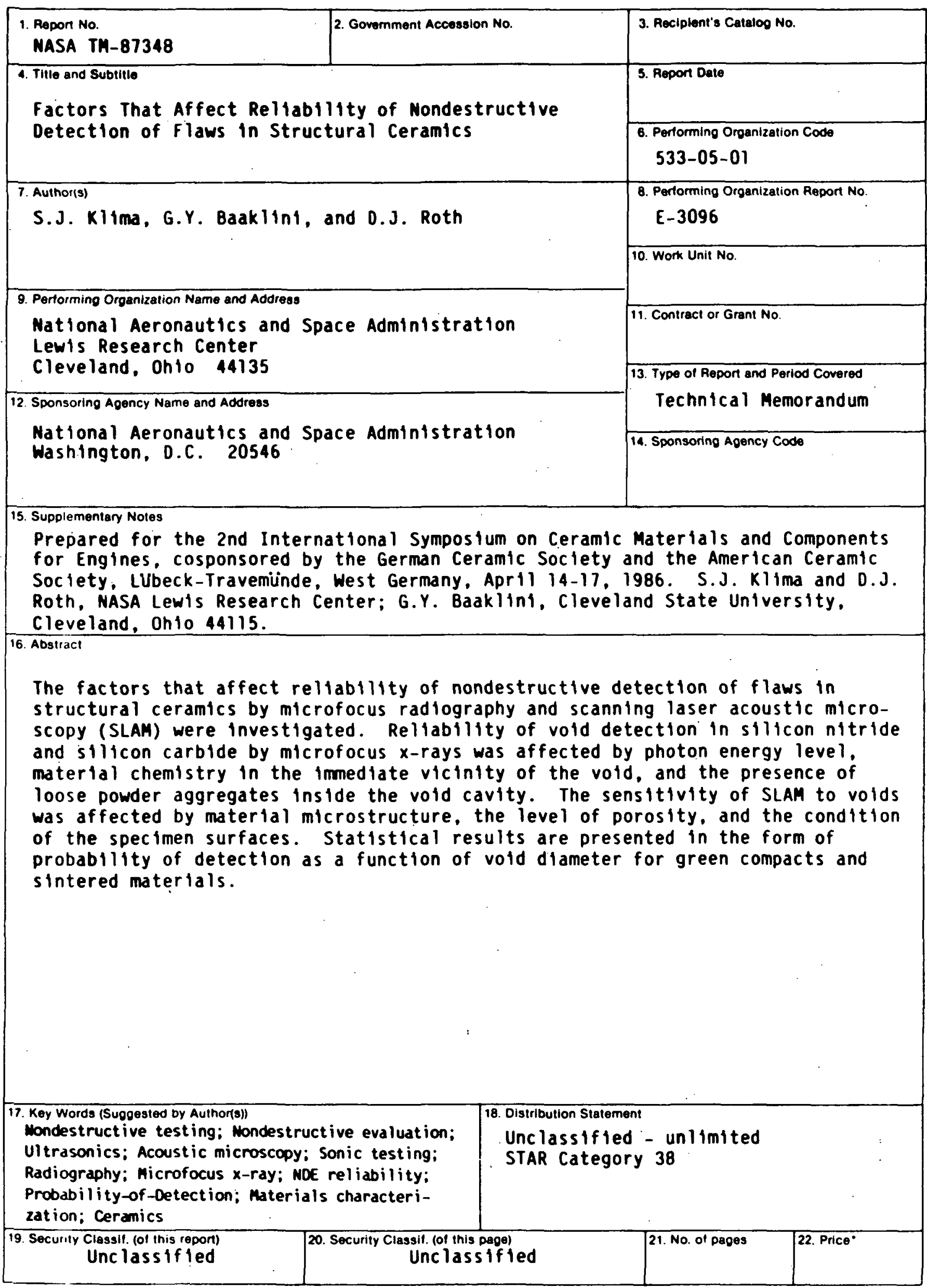

-For sale by the National Technical Information Service. Springlield. Virginia 22161 
National Aeronautics and

Space Administration

Lewis Research Center

Cleveland. Ohio 44135

Official Business

Penalty for Pitvate Uso $\$ \$ 00$
ADORESS CORRECTION REQUESTED

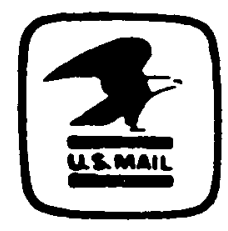

Postage and Fees Paid National Aeronautics and Space Administration NASA-451 